15 Siedel J, Schlumberger J, Klose S, Ziegenhorn J, Wahlefeld AW. Improved reagent for the enzymatic determination of serum cholesterol. $f$ Clin Chem Clin Biochem 1981;19:838-9.

16 Stahler F, Gruber W, Stinshoff J. Eine praxisgerechte enzymatische Cholesterinbestimmung. Med Lab (Stuttgart) 1977;30:29-39.

17 Bachonik PS, Walker R, Bronnel KD, Stunkard AJ, Kwiterovick PO. Determination of high density lipoprotein cholesterol. F Lipid Res 1980;21: 608-16.

18 World Health Organisation. Diabetes mellitus. WHO Tech Rep Ser $1985 ;$ No 727

19 Hughes LO, Raval U, Raftery EB. First myocardial infarctions in Asian and white men. Br Med F 1989;298:1345-50.

20 Mather HM, Keen H. The Southall diabetes survey: prevalence of known diabetes in Asians and Europeans. Br Med $\mathcal{F} 1985 ; 291: 1081-4$.

21 Cruickshank JK, Drubra U, McDuff J, Mahler RF. Metabolic data on the epidemic of glucose intolerance and diabetes among Afro-Caribbeans, whites and Gujeratis in north-west London [Abstract]. Diabetic Med 1988;5(suppl 12):31.

22 Kessler II. Mortality experience of diabetic patients: a twenty-six year follow-up study. Am $\mathcal{F}$ Med 1971;51:715-24.

23 Kannel WB, McGee DL. Diabetes and glucose tolerance as risk factors for cardiovascular disease: the Framingham study. Diabetes Care 1979;2:120-6.

24 Marks HH, Krall LP. Onset, course, prognosis and mortality in diabetes mellitus. In: Marble A, White P, Bradley RF, Krall L, eds. foslins diabetes mellitus. Philadelphia: Lea and Feibiger, 1971:209.

25 McKeigue PM, Marmot MG. Mortality from coronary heart disease in Asian communities in London. Br Med f 1988;297:903.

26 Reaven GM, Bernstein R, Davis B, Olefsky JM. Nonketotic diabetes mellitus: insulin deficiency or insulin resistance? Am $\mathcal{F}$ Med 1976;60:80-8.
27 Unger RH, Grundy S. Hyperglycaemia as an inducer as well as a consequence of impaired islet cell function and insulin resistance: implications for the management of diabetes. Diabetologia $1985 ; 26: 44-9$.

28 O'Rahilly SP, Rudenski AS, Burnett MA, et al. Beta cell dysfunction rather than insulin insensitivity is the primary defect in familial type 2 diabetes. Lancet 1986;ii:360-4.

29 Topping DL, Mayes PA. The immediate effects of insulin and fructose on the metabolism of the perfused liver. Biochem f 1972;126:295-311.

30 Nikkila EA, Kekki M. Plasma triglyceride transport kinetics in diabetes mellitus. Metabolism 1973;22:1-22.

31 Brunzell JD, Porte D, Bierman EL. Abnormal lipoprotein-lipase mediated plasma triglyceride removal in untreated diabetes mellitus associated with plasma triglyceride removal in untreated diabetes

32 Castelli WP, Doyle JT, Gordon T, et al. HDL cholesterol and other lipids in coronary heart disease. Circulation 1977;55:767-72.

33 Kannel WB. High-density lipoproteins: epidemiologic profile and risks of coronary artery disease. Am $\mathcal{F}$ Cardiol 1983;52:9-12B.

34 Castelli WP, Garrison RJ, Wilson PWF, Abbott RD, Kalousdian S, Kannel WB. Incidence of coronary heart disease and lipoprotein cholesterol levels. The Framingham study. FAMA 1986;256:2835-8.

35 Hughes LO, Cruickshank JK. Cardiovascular disease in black and Indian origin populations outside the USA. In: Cruickshank JK, Beevers DG, eds. Ethnic factors in health and disease. London: Butterworth/Wright, 1989: 257-64.

36 Temple RC, Carrington CA, Luzio SD, et al. Insulin deficiency in non-insulindependent diabetes. Lancet 1989;i:293-5.

(Accepted 19 June 1989)
Embryo and Gamete Research Group, Department of Obstetrics and Gynaecology, University of Cambridge Clinical School, Cambridge CB2 2SW

Lesley Regan, MRCOG, senior registrar

Peter R Braude, MRCOG, lecturer

Paula L Trembath, RGN research sister

Correspondence to:

Dr Lesley Regan,

Department of Obstetrics and Gynaecology, Rosie

Maternity Hospital,

Cambridge CB2 2SW

BrMed f 1989;299:541-5

\title{
Influence of past reproductive performance on risk of spontaneous abortion
}

\author{
Lesley Regan, Peter R Braude, Paula L Trembath
}

\section{Abstract}

Objective-To investigate the incidence of spontaneous abortion in a population of women in order to establish their risk of spontaneous abortion and the obstetric factors predisposing to it.

Design-Prospective study of women recruited by radio and poster appeal and from hospital outpatient clinics.

Setting-English provincial community.

Patients -630 Women from the general population intending to become pregnant.

Interventions - The viability of the pregnancy was assessed by abdominal ultrasonography before completion of the eighth week, and the assessment was repeated if vaginal bleeding occurred.

Main outcome measure-Spontaneous abortion or live births in women with or without a previous history of spontaneous abortion.

Results-The overall incidence of clinically recognisable spontaneous abortion before 20 weeks of gestation was $12 \%$ (50/407 pregnancies). The risk of spontaneous abortion in each category of patient was classified with respect to the patient's past reproductive performance and found to be influenced greatly by her previous obstetric history. In primigravidas and women with a history of consistently successful pregnancies the incidences of abortion were low $(5 \%(4 / 87)$ and $4 \%(3 / 73)$ respectively), whereas women with only unsuccessful histories had a much greater risk of aborting the study pregnancy $(24 \%(24 / 98))$, even when their sole pregnancy had ended in abortion $(20 \%(12 / 59))$. The outcome of the last pregnancy also influenced the outcome of the study pregnancy; only $5 \%$ of women (5/95) whose previous pregnancy had been successful aborted, whereas the incidence of loss of pregnancy among women whose last pregnancy had aborted was $19 \%(40 / 214)$.

Conclusions-A knowledge of the patient's reproductive history is essential for the clinical assessment of her risk of spontaneous abortion. As the most important predictive factor for spontaneous abortion is a previous abortion, the outcome of a woman's first pregnancy has profound consequences for all subsequent pregnancies.

\section{Introduction}

Spontaneous abortion is the commonest complication of pregnancy, affecting roughly one in four of all women who become pregnant.' When a patient has just lost a pregnancy, however, it is difficult to give informed advice about a likely recurrence, as in most cases the aetiology of the abortion is unknown. In practice it is usually assumed that the cause is non-recurrent and the patient reassured that the chance of her next pregnancy continuing successfully is much higher than the chance of her miscarrying again. Quantifying the risk to an individual patient of an early pregnancy loss after repeated abortions is even more difficult. Opinions differ widely about whether patients who have experienced consecutive losses suffer from a distinct clinical disorder or are simply unlucky. ${ }^{23}$ The lack of data also makes it impossible to assess the efficacy of treatment.

One problem in establishing accurate figures is the bias introduced by the selection of patients. Most reports have been retrospective, hospital based studies of pregnant women because this sampling method provides a quick way of obtaining a large pool of data. This approach, however, yields no meaningful information about loss in first pregnancies. ${ }^{145}$ In prospective studies in which a declared pregnancy forms the basis for recruitment early abortions that do not require medical intervention are underrepresented. ${ }^{6}$

The Cambridge early pregnancy loss study was undertaken with three aims: to determine the incidence of spontaneous abortion in a well documented population recruited before pregnancy; to identify factors predisposing to spontaneous abortion; and to assess the risk of recurrent abortion. The study population afforded an ideal opportunity for accurate collection of these data, as all patients in the catchment area received their antenatal care and were delivered at a single hospital. 


\section{Patients and methods}

Women in the Cambridge hospital catchment area of various ages and parities who were contemplating a pregnancy were enrolled into the study by a continuing local radio and poster appeal started in February 1986. Patients were also drawn from postnatal and subfertility clinics at Addenbrooke's Hospital, together with patients who had miscarried during the study period at the hospital. Further patients who had been referred specifically for prepregnancy counselling because of previous early complications of pregnancy or general medical disorders were included. The project was approved by Addenbrooke's Hospital district ethical committee.

All volunteers were interviewed before they became pregnant in order to document their general medical, social, gynaecological, and obstetric history and explain the nature of the study. They were asked to report immediately after their first missed menstrual period. As soon as a pregnancy was suspected the patient was seen and examined by ultrasonography using a real time abdominal sector scanner with a $2.5 \mathrm{mHz}$ transducer (Elscint ESI-1000, Israel). Blood samples in early pregnancy were taken and the serum tested for human chorionic gonadotrophin (Tandem ICON HCG, Hybritech, Europe SA). Patients developing symptoms of threatened abortion were seen immediately and further ultrasonograms obtained to confirm viability.

Serial ultrasound assessment of the pregnancy was repeated at fortnightly intervals until 12 weeks of gestation, after which arrangements were made to follow up all continuing pregnancies throughout their antenatal course. Detailed records of any complications arising in those patients with ongoing pregnancies were completed at the time of delivery.

Statistical analysis-Comparisons between groups were made by using $2 \times 2$ contingency tables. Fisher's exact test was applied when cells contained fewer than five samples. Odds ratios and $95 \%$ confidence intervals are given when appropriate.

\section{Results}

Between February 1986 and July 1988, 132 nulligravidas and 498 multigravidas were recruited to the Cambridge early pregnancy loss study. By 1 December $1988,412(65 \%)$ of the original 630 recruits had completed a pregnancy. Of these, $186(45 \%)$ had responded to the radio and poster appeal, $120(29 \%)$ had presented after a miscarriage at the hospital, and $69(17 \%)$ had been recruited from the infertility clinic (including 34 patients participating in the in vitro fertilisation or gamete intrafallopian transfer programme). The remaining 37 women $(9 \%)$ had been referred because of problems with one or more previous pregnancies or because of general medical disorders. Nineteen of these women $5 \%$ of the total pregnancies) were classified as recurrent aborters, defined as having suffered three consecutive losses before 20 weeks of gestation. Of the 186 patients recruited by the radio appeal, $52(28 \%)$ were nulligravidas, $72(39 \%)$ had a history solely of successful pregnancies, and only $17(9 \%)$ had an obstetric history which contained a spontaneous abortion ( $4 \%$ of the total population).

During recruitment volunteers were contacted by telephone every six months after enrolment if they had not already reported a pregnancy. Only five pregnancies were identified by this method. Two of these were in patients who had moved out of the area. Nine patients failed to conceive after unprotected sexual intercourse over 18 months. A further two patients were lost to follow up. Attempts at pregnancy were discontinued by two patients because of advanced age.
CLINICAL OUTCOME OF 412 PREGNANCIES

There were 357 successful pregnancies, 50 spontaneous abortions, two ectopic pregnancies, and three pregnancies requiring therapeutic termination for fetal abnormality. Spontaneous abortion was defined as the expulsion of a fetus before 20 weeks of gestation or weighing less than $500 \mathrm{~g}$ (World Health Organisation criteria). ${ }^{8}$ The ectopic pregnancies and therapeutic terminations are excluded from the analysis of factors affecting the incidence of spontaneous abortion. The analyses reported below are therefore based on 407 pregnancies -50 ending in spontaneous abortion and 357 resulting in live births.

Pregnancy was confirmed by ultrasonography in $95 \%$ of patients before the eighth week, by which time $24(48 \%)$ of the abortions had occurred. All but two of the 50 spontaneous abortions occurred in the first trimester, the remaining two occurring at 13 and 17 weeks, respectively.

The overall incidence of spontaneous abortion in the total population was $12 \%$. Among the 87 pregnancies in primigravidas only four ended in abortion $(5 \%)$, whereas 46 of the 320 multigravidas suffered a spontaneous abortion (14\%). This may suggest that women embarking on their first pregnancy have the lowest risk of spontaneous abortion $\left(\chi^{2}=5 \cdot 19 ; p=0 \cdot 02\right.$; odds ratio $3 \cdot 48,95 \%$ confidence interval $1 \cdot 2$ to $10 \cdot 2$ ) and that gravidity is a useful measure of risk. But when the multigravidas recruited after a recent miscarriage at the hospital were excluded from the gravidity analysis the increased incidence of abortion with higher gravidity was no longer significant $\left(\chi^{2}=1 \cdot 39 ; \mathrm{p}=0 \cdot 2\right.$; odds ratio $2 \cdot 2,95 \%$ confidence interval $0 \cdot 7$ to $8 \cdot 1$ ).

Eighty one of the 407 pregnancies resulted after treatment for subfertility (33 in primigravidas, 48 in multigravidas). Sixty nine patients were recruited directly from the subfertility clinic and 12 had received treatment for subfertility from their general practitioners. Among these 81 patients there were 13 spontaneous abortions (16\%), which did not differ significantly from the loss rate of the spontaneous pregnancies $(11 \% ; 37$ abortions after 326 spontaneous conceptions $-\chi^{2}=0.93 ; p=0 \cdot 3$; odds ratio $0.67,95 \%$ confidence interval 0.32 to $1 \cdot 4$ ). Only one spontaneous abortion (3\%), however, occurred among the 33 primigravidas treated successfully for subfertility, an incidence substantially lower than the $25 \%$ loss noted among the multigravidas treated for subfertility ( 12 abortions after 48 conceptions $-\chi^{2}=5 \cdot 47 ; p=0 \cdot 02$; odds ratio $11 \cdot 1,95 \%$ confidence interval $1 \cdot 29$ to $76 \cdot 92$ ). Only one of the 34 pregnancies resulting after in vitro fertilisation or gamete intrafallopian transfer aborted, whereas nine of the 30 conceptions $(30 \%)$ induced by clomiphene ended in spontaneous abortion. One abortion occurred in a patient treated with bromocriptine (three patients had been treated with this drug), one in a patient treated with gonadorelin (four patients had received this treatment), and the remaining abortions occurred in a patient with male factor subfertility (10 patients had this problem).

\section{NON-INFLUENTIAL FACTORS}

The mean age of the total study population of mothers was 29.6 years (SD 4.5). There was no significant difference in mean age between the 326 mothers with spontaneous pregnancies $(29 \cdot 4$ (SD $4.5)$ years) and the 81 treated for subfertility (30.7 $(4 \cdot 6))$. There was no appreciable increase in the incidence of spontaneous abortion at either end of the reproductive age range, though only three patients were under 20 and only 25 older than 38 . The mean age of the 50 women who aborted $(29 \cdot 7$ (SD 5.1) years) was the same as that of the women whose pregnancies were successful $(29 \cdot 6(4 \cdot 2)$ years $)$. No significant association was identified between the risk of spontaneous 
abortion and social class, smoking habit, drug ingestion, contraceptive usage, previous therapeutic termination of pregnancy, or past medical history.

PAST REPRODUCTIVE HISTORY AND RISK OF ABORTION

Table I lists the 50 study pregnancies ending in spontaneous abortion categorised by the patient's previous reproductive history and subdivided into spontaneous conceptions $(\mathrm{n}=37)$ and assisted conceptions $(n=13)$

Of the 50 spontaneous abortions, 40 occurred in women whose previous pregnancy had ended in an abortion. Twenty four women had had only unsuccessful pregnancies, and 12 patients' sole previous pregnancy had ended in spontaneous abortion. In contrast, only five patients whose last pregnancy had resulted in a live birth aborted. Among the primigravidas the incidence of spontaneous abortion was $8 \%(4 / 50)$, and among those women who had had only successful pregnancies in the past the incidence was $6 \%(3 / 50)$. There were two spontaneous abortions among the 32 patients whose previous reproductive history contained a termination of pregnancy. The five patients whose obstetric history included an ectopic pregnancy were excluded from this part of the analysis. Though the numbers of patients treated for subfertility were small, Fisher's exact test showed no significant difference between the two subgroups who conceived spontaneously and after treatment for subfertility within the different categories of reproductive history. In both subgroups, however, the difference in the incidence of abortion between primigravidas and women who had suffered previous abortions was substantial (table I).

As past reproductive performance seemed to be an important contributory factor in the risk of abortion the same analysis was applied to the study group as a whole. Table II shows the risk of abortion classified solely on the patient's reproductive history for all 407 pregnancies studied. Table III shows the risk of abortion among the 326 pregnancies conceived spontaneously. Patients whose last pregnancy had ended in an abortion had a 19\% chance of aborting the study pregnancy (table II), a significantly higher risk than primigravidas $(5 \%)$, women whose pregnancies had all been successful (4\%), and patients whose las pregnancy had been successful $(5 \%)$. The greatest risk

TABLE I-Outcome of study pregnancy categorised by mother' reproductive history

\begin{tabular}{|c|c|c|c|}
\hline \multirow[b]{2}{*}{ History } & \multicolumn{3}{|c|}{ No (\%) of patients aborting } \\
\hline & $\begin{array}{l}\text { Entire } \\
\text { group } \\
(\mathbf{n}=50)\end{array}$ & $\begin{array}{c}\text { Spontaneous } \\
\text { conceptions } \\
(\mathrm{n}=37)\end{array}$ & $\begin{array}{c}\text { Assisted } \\
\text { conceptions } \\
(\mathbf{n}=13)\end{array}$ \\
\hline Last pregnancy aborted & $40(80)^{2}$ & $31(84)^{\mathrm{h}}$ & $9(69)^{t}$ \\
\hline Only abortions in the past & $24(48)$ & $17(46)^{k}$ & $7(54)^{n}$ \\
\hline Only pregnancy aborted & $12(24)^{c}$ & $7(19)$ & $4(31)$ \\
\hline Last pregnancy successful & $5(10)^{h}$ & $3(8)^{\prime}$ & $2(15)$ \\
\hline All pregnancies successful & $3(6)^{t}$ & $2(5)$ & $1(8)$ \\
\hline Only pregnancy successful & $3(6)$ & $2(5)$ & $1(8)$ \\
\hline Previous termination of pregnancy & $2(4)$ & $1(3)$ & $1(8)$ \\
\hline Primigravida & $4(8)^{n}$ & $3(8)$ & $1(8)^{\mathrm{m}}$ \\
\hline
\end{tabular}

a $v$ b: $\chi^{\prime}=46 \cdot 7 ; \mathrm{p}<0 \cdot 000001 ;$ odds ratio $36,95 \%$ confidence interval $10 \cdot 1$ to $138 \cdot 5$.

c $v$ d: $\gamma^{2}=20 \cdot 29 ; p=0 \cdot 000007 ;$ odds ratio $14 \cdot 5,95 \%$ confidence interval $3 \cdot 6$ c $v \mathrm{~d}: \gamma$

e $\mathrm{f}: \chi^{2}=5 \cdot 02 . \mathrm{p}=0.03$; odds ratio $4.9,95 \%$ confidence interval 1.2 to 20.0 e $v \mathrm{f:}: \chi=5 \cdot 02 ; \mathrm{p}=0.03 ;$ odds ratio $4.9,95 \%$ confidence interval $1 \cdot 2$ to $20 \cdot 0$.
a $v \mathrm{~g}: \gamma^{2}=49 \cdot 72 ; \mathrm{p}<0.000001 ;$ odds ratio $46,95 \%$ confidence interval 11.9 to a $v$ g:

c $v \mathrm{~g}: \chi^{2}=17 \cdot 9 ; \mathrm{p}=0.00002 ;$ odds ratio $10 \cdot 6,95 \%$ confidence interval 3.0 to

$\mathrm{h} v \mathrm{i}: \chi:=39 \cdot 67 ; \mathrm{p}<0 \cdot 000001 ;$ odds ratio $58 \cdot 6,95 \%$ confidence interval $11 \cdot 6$ to $207: 8$

h $v$ i: $y:=39 \cdot 67 ; \mathrm{p}<0 \cdot 000001 ;$ odds ratio $58 \cdot 6,95 \%$ confidence interval $11 \cdot 6$ $10207: 8$

$\mathrm{k} v \mathrm{j}: \chi^{2}=11 \cdot 58 ; \mathrm{p}=0 \cdot 00067$; odds ratio $9 \cdot 6,95 \%$ confidence interval $2 \cdot 2$ to $35 \cdot 5$.

$\mathrm{l} v \mathrm{~m}: \gamma^{\prime}=7 \cdot 96 ; \mathrm{p}=0 \cdot 0047$; odds ratio $27,95 \%$ confidence interval $2 \cdot 1$ to $266 \cdot 4$.

$\mathrm{m} v \mathrm{n}: \gamma^{2}=4.51 ; \mathrm{p}=0.045 ;$ odds ratio $14,95 \%$ confidence interval 1.2 to $159 \cdot 8$.
TARLE II-Effect of mother's reproductive history on risk of spontaneous abortion: entire group $(n=407)$

\begin{tabular}{cccc}
\hline Ho of & $\begin{array}{c}\text { Total } \\
\text { patients } \\
\text { aborting }\end{array}$ & $\begin{array}{c}\text { No of } \\
\text { patients }\end{array}$ & $\begin{array}{c}\text { abortion in } \\
\text { atudy pregnancy }\end{array}$ \\
\hline
\end{tabular}

Last pregnancy aborted
Only abortions in the past
Only pregnancy aborted
Last pregnancy successul
All pregnancies succesful
Only pregnancy successful
Previous termination of pregnancy
Primigravida

$\begin{array}{rrr}40 & 214 & 19 \\ 24 & 98 & 24 \\ 12 & 59 & 20 \\ 5 & 95 & 5^{n} \\ 3 & 73 & 4^{\prime} \\ 3 & 62 & 5^{\prime} \\ 2 & 32 & 6 \\ 4 & 87 & 5^{\circ}\end{array}$

a $v$ b: $\chi_{:}^{\prime}=8 \cdot 32 ; \mathrm{p}=0.004 ;$ odd ratio $4 \cdot 1,95 \%$ confidence interval $1 \cdot 5$ to $12 \cdot 2$. c $v$ d: $\gamma_{0}^{\prime}=11 \cdot 2 ; p=0.0008$; odds ratio $7 \cdot 4,95 \%$ confidence interval 2.0 to $23 \cdot 7$

e $v$ f: $\chi^{2}=5 \cdot 34 ; \mathrm{p}=0 \cdot 02 ;$ odds ratio $5 \cdot 0,95 \%$ confidence interval $1 \cdot 2$ to $19 \cdot 7$. a $v \mathrm{~g}: \chi^{2}=8 \cdot 75 ; \mathrm{p}=0.003$; odds ratio $4 \cdot 8,95 \%$ confidence interval 1.6 to $13 \cdot 4$. c v g: $\chi^{2}=12 \cdot 69 ; \mathrm{p}=0 \cdot 00036$; odds ratio $6 \cdot 7,95 \%$ confidence interval $2 \cdot 1$ to $24 \cdot 1$. e $\mathrm{g}: \gamma^{\prime}=7 \cdot 39 ; \mathrm{p}=0 \cdot 0065 ;$ odds ratio $5 \cdot 3,95 \%$ confidence interval 1.5 to $20 \cdot 8$

TABLE III-Effect of mother's reproductive history on risk of spontaneous abortion: spontaneous conceptions only $(n=326)$

\begin{tabular}{cccc}
\hline No of & $\begin{array}{c}\text { Total } \\
\text { patients } \\
\text { aborting }\end{array}$ & $\begin{array}{c}\text { \%o Risk of } \\
\text { patients }\end{array}$ & $\begin{array}{c}\text { abortion in } \\
\text { study pregnancy }\end{array}$ \\
\hline
\end{tabular}

Last pregnancy aborted

Only abortions in the past

Only pregnancy aborted

Last pregnancy successful

All pregnancies successful

Only pregnancy successful

Previous termination of pregnancy

Primigravida

$\begin{array}{rrr}31 & 187 & 17^{\circ} \\ 17 & 78 & 22^{\circ} \\ 8 & 47 & 17^{\mathrm{c}} \\ 3 & 77 & 4^{\mathrm{b}} \\ 2 & 58 & 3^{\mathrm{a}} \\ 2 & 49 & 4^{\prime} \\ 1 & 29 & 3 \\ 13 & 154 & 16^{\mathrm{a}} \\ \end{array}$

$v$ b: $\gamma^{\prime}=6 \cdot 73 ; \mathrm{p}=0 \cdot 0009 ;$ odds ratio $4 \cdot 9,95 \%$ confidence interval 1.4 to $16 \cdot 3$.

c $v$ d: $\chi^{2}=7 \cdot 85 ; p=0 \cdot 005 ;$ odds ratio $7 \cdot 8,95 \%$ confidence interval $1 \cdot 6$ to $32 \cdot 8$. e $v$ f: $\chi^{2}=3 \cdot 03 ; \mathrm{p}=0.08$; odds ratio $4 \cdot 8,95 \%$ confidence interval $0 \cdot 8$ to $28 \cdot 3$. (Fisher's exact test, $\mathrm{p}=0 \cdot 04$.)

a $v \mathrm{~g}: \chi^{2}=3.34 ; \mathrm{p}=0.067$; odds ratio $3.4,95 \%$ confidence interval 0.9 to 12.5 c $v \mathrm{~g}: \chi^{2}=5 \cdot 34 ; \mathrm{p}=0 \cdot 02$; odds ratio $4 \cdot 7,95 \%$ confidence interval $1 \cdot 2$ to $17 \cdot 7$

of abortion (24\%) occurred in patients whose obstetric histories contained only abortions. The risks in pregnancies conceived spontaneously were similar (table III), though the confidence intervals were wider owing to the reduction in sample size.

\section{Discussion}

It is generally quoted that $15 \%$ of clinically recognised pregnancies abort spontaneously. ${ }^{1910}$ This figure, however, may be an underestimate, as most studies have been based on data collected retrospectively from hospital populations. ${ }^{6711}$ In these studies early spontaneous abortions are likely to be underrepresented because symptoms of early abortion tend to be mild and the patient is less likely to seek specialist advice. ${ }^{17}$ On the other hand, prospective studies that recruit patients who are already pregnant may exaggerate the incidence of loss, as symptoms of threatened abortion will encourage earlier presentation of "at risk" pregnancies. ${ }^{12} 13$

The overall incidence of early loss of pregnancy in this study $(12 \% ; 50 / 407$ pregnancies $)$ was slightly lower than reported generally but agrees with a recent study in which patients were also enrolled prospectively before pregnancy $(12 \%) .{ }^{14}$ We believe that this figure reflects the true incidence of clinical spontaneous abortion in our study population, as $(a)$ the drop out rate of recruits was very low $(18$, of whom half were "failures to conceive"); (b) we achieved a diagnosis of pregnancy successfully in $95 \%$ of patients before the eighth week; and $(c)$ the study design ensured reporting of early clinical abortions, such that 24 of the 50 reported had occurred before the eighth week. No attempt was made to assess the contribution of subclinical abortion..$^{14} 15$

Our finding from a prospective study that a woman's 
risk of spontaneous abortion may be quantified by looking at her past obstetric history has not been reported before, and the tables of risks (tables II and III) will be of use to practising physicians. Primigravidas, women whose pregnancies have all been successful, and women whose last pregnancy was completed successfully all have a low incidence of spontaneous abortion. The outcome of the last pregnancy is also an important predictive factor for spontaneous abortion; the risk of spontaneous abortion in women whose last pregnancy was unsuccessful was substantially higher than in women whose last pregnancy was successful. In this regard the use of gravidity grouping to classify the outcome of pregnancy may be misleading. This method ignores whether the previous pregnancies were successful or unsuccessful and encourages the clustering of women suffering several miscarriages within the higher gravidity groups, which by definition will occur at progressively older ages. This is one reason why previous studies of the risk of recurrence that have not taken the outcome of previous pregnancies into account have quoted such variable figures. ${ }^{510}$

Our finding that primigravidas have a low incidence of spontaneous clinical abortion has also not been reported previously in a population recruited prospectively. This study included 87 primigravidas, of whom only 33 had received treatment for subfertility. Those studies that concluded that abortion was more common in first pregnancies ${ }^{101617}$ were retrospective and suffered from the inadequacies referred to above. More recent attempts to establish the incidence of abortion in primigravidas have been made solely from programmes of assisted fertility, where the incidence of spontaneous abortion ranges from $12 \%$ to $45 \%$. $^{18-21}$ The suggestion that the method used to aid conception in subfertile couples might affect the frequency of subsequent loss of pregnancy"2 is confirmed in part by the results of this study, in which the incidence of abortion in patients treated with clomiphene was over twice the average. The possibility that the higher incidence of spontaneous abortion quoted for first pregnancies in patients treated for infertility reflects the more detailed periconceptual observation usually employed for such patients ${ }^{2021}$ does not apply to this study, as all our patients received the same surveillance in early pregnancy. Our finding that pregnancies in primigravidas, whether a result of natural or assisted conception, shared the same low risk of spontaneous abortion as those in multigravidas suggests that it is the past reproductive history rather than the treatment of infertility alone that influences the subsequent outcome of pregnancy.

The characteristic J shaped curve of fetal loss associated with rising maternal age $\mathrm{a}^{23}$ was not evident in our study, probably because of the small numbers of patients in the older age groups.

The mechanism by which past obstetric history might influence the outcome of subsequent pregnancies is not clear. Nevertheless, it is important to note that the risk of the study pregnancy ending in abortion among patients whose last pregnancy had a successful outcome was similar to that both among women whose pregnancies had consistently been successful and among the primigravidas. Thus we might postulate that a successful pregnancy does not exert a "protective effect," but rather that those patients who abort spontaneously do so because some factor which would allow pregnancy to continue is lacking. Persistent lack of this factor would lead to recurrent spontaneous abortion.

Several hypotheses have been advanced in support of such an "absent factor" type of mechanism. Blocking antibodies which can inhibit the mixed lymphocyte reaction and are present in serum samples from multiparous women are claimed to be either absent or present only in low titres in samples from women with recurrent abortions. ${ }^{2425}$ It has also been suggested that increased sharing of HLA antigens ${ }^{26}{ }^{27}$ or HLA linked antigens ${ }^{28}$ between partners may be important in the aetiology of spontaneous abortion. It would be plausible to implicate this type of mechanism in loss of pregnancy after previous spontaneous abortion; women who share some HLA types with their partner would have a variable outcome of their pregnancy depending on the segregation of their genotype but overall would be expected to do worse than couples with wholly dissimilar tissue types. McLaren's examination of controlled data from animal studies, ${ }^{29}$ however, cast doubt on the original hypothesis ${ }^{30}$ on which these immunological theories are based, and subsequent clinical studies also failed to substantiate the theory. ${ }^{31-34}$

Clarke et al proposed that residual material in the uterus after a spontaneous abortion might affect a subsequent pregnancy. ${ }^{35}$ They postulated that trophoblastic cell "rests" influenced the outcome of subsequent pregnancies, as spina bifida and anencephaly were more common in patients whose last pregnancy had ended in abortion as compared with matched controls in whom the outcome had been a normal baby. ${ }^{35} 36$

The possibility that our results reflect selection bias in the population studied demands careful evaluation. Despite the fact that $45 \%$ of the patients were recruited from the radio appeal and thus might have represented a self selected group with a previous history of abortion, this was not found to be the case; only $9 \%$ of this group had a history containing an abortion, whereas $28 \%$ were primigravidas and $39 \%$ had had only successful pregnancies in the past. Including patients after a recent miscarriage at the hospital $(n=120)$ or who had suffered problems during a previous pregnancy $(n=37)$ could also bias the results. After excluding these 157 patients, however, the proportions in the various groups shown in tables II and III were unchanged (data not shown). We are also aware that our catchment area includes a group of middle class, well motivated patients who may well have an inherently lower risk of spontaneous abortion. Furthermore, the contribution that careful periconceptual medical supervision and "tender loving care" may have played in reducing the frequency of spontaneous abortion among the primigravidas, and in particular the patients treated for infertility, are very difficult to assess objectively. The Norwegian follow up study of recurrent aborters found that the outcome of subsequent pregnancy was successful in $86 \%$ of women receiving specialised antenatal counselling and psychological support compared with a success rate of only $33 \%$ in women given no specific care. ${ }^{37}$

Despite these cautions our results have important implications for our clinical practice. It is clear that reproductive history is of prime importance in establishing the risk of losing a pregnancy, for it seems that the most relevant predictive factor for spontaneous abortion is an abortion in the previous pregnancy. The risk of spontaneous abortion among primigravidas is low and, in contrast with previously held ideas, is also low for patients treated for primary infertility. Thus the outcome of the first pregnancy may affect substantially the woman's entire subsequent reproductive performance.

For the woman who has miscarried recently the customary medical counsel that "next time will be all right" needs to be revised, as our findings show that this advice may be misleading. Further studies are needed in order to identify those factors which determine whether a first pregnancy will result in success or failure, with the aim of being able to 
offer prophylactic preconceptual counselling to all nulligravidas.

We thank John Summerfield and Martin Johnson for constructive criticism of the manuscript, Janet Cooper for keeping track.of the patients, and the women who took part, without whose cooperation and enthusiasm the study would not have been possible. The study was supported by a programme grant (G 8302273) from the Medical Research Council to PRB and Dr M H Johnson.

1 Warburton D, Fraser FC. Spontaneous abortion risks in man: data from reproductive histories collected in a medical genetics unit. Hum (iene 1964;16:1-25

2 Huisjes HJ. Spontaneous abortion. Edinburgh: Churchill Livingstone, 1984

3 Malpas P. A study of abortion sequences. Journal of Obstetrics and Gynuecologv of the British Empire 1938;45:932-49.

4 Naylor AF. Sequential aspects of spontaneous abortion: maternal age, parity and pregnancy compensation artefact. Soc Biol 1974;21:195-204.

5 Naylor AF, Warburton D. Sequential analysis of spontaneous abortion. II. Collaborative study data show that gravidity determines a very substantial rise in risk. Fertil Steril 1979;31:282-6.

6 Roth DB. The frequency of spontaneous abortion. Int 7 Fertil 1963;8:434-7.

7 Harlap S, Shiono PH, Ramcharan S. A life table of spontaneous abortions and the effects of age, parity and other variables. In: Porter IH, Hook EB, eds. Embryonic and fetal death. New York: Academic Press, 1980:145-58.

8 World Health Organisation. Recommended definitions, terminology and format for statistical tables related to the perinatal period. Acta Obstet Gynecol Scand 1977;56:247-53.

9 Petersson F. Epidemiology of early pregnancy wastage. Stockholm: Svenska Bokförlaget, 1968.

10 Poland BJ, Miller JR, Jones DC, Trimble BK. Reproductive counselling in patients who have had a spontaneous abortion. Am $f$ Obstet Gynecol 1977; 127:685-91

1 Javert CT. Spontaneous and habitual abortion. New York: McGraw-Hill, 1957.

12 French FE, Bierman JM. Probabilities of fetal mortality. Public Health Rep $1962 ; 77: 835-47$

13 Shapiro S, Levine HS, Abramowicz M. Factors associated with early and late fetal loss. Advances in Planned Parenthood 1971;6:45-58.

14 Wilcox AJ, Weinberg CR, O'Connor JF, et al. Incidence of early loss of pregnancy. N Englf Med 1988;319:189-94.

15 Walker EM L pregnancy: fact or fiction? Br f Obstet Gynaecol 1988;95:659-63. pregnancy. fact or fiction? Brf Obstel Gynaecol 1988,95.659 63.

Awan AK. Some biologic

7 Clas RH, Golbus MS. Habitual abortion. Fertil Steril 1978:29:257-65.

18 Chartier M, Roger M, Barrat J, Michelon B. Measurement of plasma human chorionic gonadotropin (hCG) and beta-hCG activities in the late lutea phase: evidence of the occurrence of spontaneous menstrual abortion in infertile women. Fertil Steril 1979;31:134-7.
9 Lopata $A$. Successes and failures in human in vitro fertilisation. Nature 980;288:6+2-3

20 Frydman R, Testart J, Lassalle B, Kerbrat G, Chasseray JE, Papiernik B. Transfert uterin d un seuf féconde in vitro: avortement spontane. Nioucell Presse . Medicale 1981;10:3475-6.

21 Ben-Rafacl Z, Fateh M, Flickinger (iL, Tureck R, Blasco L, Mastroianni I. Incidence of abortion in pregnancies after in vitro fertilisation and embryo transfer. (Obstet (Gynecol 1988;71:297-300.

22 Jansen RPS. Spontaneous abortion incidence in the treatment of infertility. Am J Obstet (jynecol 1982;143:451-73.

23 Roman EA, Alberman E, Pharoah POD. Pregnancy order and reproductive loss. Br.Med f 1980;280:715

24 Rocklin RE, Kitzmiller JL, Carpenter CB, Garovoy MR, David JR. Maternal-fetal relation. Absence of an immunologic blocking factor from the Maternal-ctal relaton. Absence of an immologic blocking factor from

Stimson $\mathrm{WH}$, Strachan AF, Shepherd A. Studies on the maternal immune response to placental antigens: absence of a blocking factor from the bloed of response to placental antigens: absence of a blocking factor

26 Komlos L, Zamir R, Joshua H, Halbrecht I. Common HLA antigens in couples with repeated abortions. Clin Immunol Immunopathol 1977;7:330-5.

27 Gerencer M, Drazanic A, Kuvacic I, Tomaskovic Z, Kastelan A. HLA antigen studies in women with recurrent gestational disorders. Firtil Steril 1979;31 $401-4$

28 Power DA, Catto GRD, Mason RJ, et al. The fetus as an allograft: evidence for protective antibodies to HLA-linked paternal antigens. Lancet 1983;ii: 701-4.

29 McLaren A. Antigenic disparity: does it affect placental size, implantation or population genetics? In: Edwards RG, Howe CWS, Johnson MH, eds. Immunobiology of trophoblast. Cambridge: Cambridge University Press, 1975:225-73.

30 Clarke B, Kirby DRS. Maintenance of histocompatibility polymorphisms. Vature 1974:211:999-1000.

31 Caudle MR, Rote NS, Scot JR, DeWitt C, Barney MF. Histocompatibility in couples with recurrent spontaneous abortion and normal fertility. Fertil Steril 1983:39:793-8.

32 Oksenberg JR, Persitz E, Amar A, Brautbar C. Maternal-paternal histocompatibility: lack of association with habitual abortions. Fertil Steril 1984;42:389-95

33 Adinolfi $M$. Recurrent habitual abortion, HLA sharing and deliberate immunisation with partner's cells: a controversial topic. Hum Reprod 1986;1:45-8.

34 Jazwinska EC, Kilpatrick DC, Smart GE, Liston WA. Feto-maternal HLA compatibility does not have a major influence on human pregnancy except for lymphocytotoxin production. Clin Exp Immunol 1987;68:116-22.

35 Clarke CA, Hobson D, McKendrick OM, Rogers SC, Sheppard PM. Spina bifida and anencephaly: miscarriage as possible cause. $\mathrm{Br} \mathrm{Med} \mathcal{f}$ 1975;iv: $743-6$

36 Gardiner A, Clarke CA, Cowen J, Finn R, McKendrick OM. Spontaneous abortion and fetal abnormality in subsequent pregnancy. Br. Med $\mathcal{f}$ $1978 ; \mathrm{i}: 1016-8$.

37 Stray-Pederson B, Stray-Pederson S. Ftiologic factors and subsequent reproductive performance in 195 couples with a prior history of habitual abortion. Am f Obstet Gynecol 1984;148:140-6.

(Accepted 26 fune 1989)
Oxford Region Child

Development Project, Maternity Department, John Radcliffe Hospital, Oxford OX3 9DU

Ann Johnson, MD, medical coordinator

\section{Oxford Eye Hospital,} Oxford

Maureen Stayte, DBO(D),

orthoptist

Oxford District Orthoptic

Services, Radcliffe

Infirmary, Oxford

Catherine Wortham, DBO(D)

head orthoptist

Correspondence to:

Dr Johnson.

BrMed f 1989;299:545-9

\section{Vision screening at 8 and 18 months}

\section{Ann Johnson, Maureen Stayte, Catherine Wortham on behalf of the Steering Committee of Oxford}

Region Child Development Project

\section{Abstract}

Objective-To determine the effectiveness of an existing screening programme based in the community for ocular and vision defects in infants considered at increased risk of such defects.

Design-Children with ocular or vision defect by the age of 2 were ascertained by searching records. Those from populations at high risk were matched with their results from screening tests. The characteristics of the cases among this population were compared with those of the cases in the remainder of the population. Patterns of referral and age at referral were studied in both groups.

Setting-The study was conducted within Oxfordshire Health District.

Subjects - 433 Children at high risk born in 1984 to mothers living in the health district at delivery and who either weighed less than $2000 \mathrm{~g}$ or weighed $2000 \mathrm{~g}$ and over and required admission to a special care nursery for longer than $\mathbf{2 4}$ hours. The low risk population (6254) were infants without these characteristics who were resident in the health district at the time of referral.

Interventions-Screening tests for vision or ocular defects already routinely used were applied by health visitors at 8 and 18 months to the children at high risk.
Main outcome measure-Comparison of results of screening tests with vision and ocular defects detected by the age of 2 .

Results-Screening tests in current use for vision loss and squint in this age group were insensitive and had a low positive predictive value when applied to a high risk population. Defects that were not apparent on direct inspection were unlikely to be detected by these tests. In the high risk group the relative risk of having a defect was 2.8 (95\% confidence interval 1.8 to 4.5 ) but $85 \%$ of all cases detected by the age of 2 were in children at low risk. Referral patterns and age of referral differed in the two groups.

Conclusions -Screening by health visitors of high risk populations contributes little to the detection of vision and ocular defects. This type of evaluation needs to be applied also to low risk populations, who have different referral patterns and contribute most of the cases.

\section{Introduction}

Vision screening of preschool children has become a much debated and contentious issue. Earlier claims of the likely benefits of screening' have been challenged by ophthalmologists, paediatricians, and community doctors. ${ }^{2-4}$ The term vision screening covers several 